\title{
The effects of LEDs and duty ratio on the growth and physiological responses of Silene capitata Kom., endangered plant, in a plant factory
}

Jae-Hoon Park ${ }^{1,2}$, Eung-Pill Lee ${ }^{1}$, Young-Sub Han ${ }^{1,3}$, Soo-In Lee ${ }^{1}$, Kyu-Tae Cho', Yong-Sik Hong and Young-Han You ${ }^{1 *}$ (D)

\begin{abstract}
Background: In this study, we observed their growth and physiological responses using a variety of duty ratio under the mixed light using red, blue, and white lights. The red+blue mixed light was treated with 95\%, 90\%, 85\%, $80 \%$, and $75 \%$ duty ratios and red+blue+white mixed light with $85 \%$ and $70 \%$ duty ratios. We examined the width and length of leaves, total number of leaves, and number of shoots to examine their growth responses. The physiological responses were studied by measuring their photosynthetic rate, transpiration rate, stomatal conductance, water use efficiency, chlorophyll content, and fluorescence $\left(F_{0}, F_{m}\right.$ and $\left.F_{v} / F_{m}\right)$.

Results: We found that lower duty ratio caused the length and width of the leaves to grow longer under red+blue mixed light but that it did not cause any difference in the red+blue+white mixed light condition. In addition, there was no difference in the number of leaves and shoots among all treatments. In the red+blue mixed light condition, the photosynthetic rate was no difference, but both transpiration rate and stomatal conductance were the highest at $95 \%$ duty ratio than in other ratios. Water use efficiency pattern was similar to that of photosynthetic rate; water use efficiency was no difference. Chlorophyll content was the highest at $95 \%$ duty ratios, and it was the least at $90 \%, 85 \%$, and $75 \%$ duty ratio. $F_{0}$ and $F_{m}$ values were relatively high at $85 \%$ and $80 \%$ duty ratio and low at $90 \%$ duty ratio while $F_{v} / F_{m}$ showed no difference.

Conclusions: Under the red+blue+white mixed light, all physiological items showed no difference between 70 and $85 \%$ treatments. But, photosynthetic rate, water use efficiency, chlorophyll content, and $F_{v} / F_{m}$ were relatively greater in the red+blue+white mixed light than in the red+blue mixed light. Therefore, red+blue+white mixed light treated with $70 \%$ duty ratio could lessen the environmental stress and save more power when cultivating Silene capitata in a plant factory.
\end{abstract}

Keywords: Caryophyllaceae, Ecophysiological response, Environmental tolerance, Indoor plant, Light quality

\footnotetext{
* Correspondence: youeco21@kongju.ac.kr

${ }^{1}$ Department of Biological Science, Kongju National University, Gongju-si

32588, Chungcheongnam-do, Republic of Korea

Full list of author information is available at the end of the article
}

(c) The Author(s). 2018 Open Access This article is distributed under the terms of the Creative Commons Attribution 4.0 International License (http://creativecommons.org/licenses/by/4.0/), which permits unrestricted use, distribution, and reproduction in any medium, provided you give appropriate credit to the original author(s) and the source, provide a link to the Creative Commons license, and indicate if changes were made. The Creative Commons Public Domain Dedication waiver (http://creativecommons.org/publicdomain/zero/1.0/) applies to the data made available in this article, unless otherwise stated. 


\section{Background}

Climate change, a global issue, increased the global annual temperature by $0.85{ }^{\circ} \mathrm{C}$ from 1880 to 2012 and the average global sea level by $19 \mathrm{~cm}$ from 1901 to 2010 (Ministry of Environment 2017). Moreover, it was reported that the area of Arctic Sea Ice is declining at a rate of $3.5-4.1 \%$ per decade (Ministry of Environment 2017). The increasing pattern of annual temperature and sea level is observed in Korea as well. The annual temperature in Korea increased by $0.23{ }^{\circ} \mathrm{C}$ per decade from 1954 to $1999,0.41{ }^{\circ} \mathrm{C}$ per decade from 1981 to 2010, and $0.5{ }^{\circ} \mathrm{C}$ per decade from 2001 to 2010 (Ministry of Environment 2017). If the current trend follows the RCP 8.5 scenario, the domestic temperature between 2017 and 2100 is expected to rise by $5.3^{\circ} \mathrm{C}$ compared to the present temperature (Ministry of Environment 2017). These environmental changes can lead to an extreme weather conditions (Houghton et al. 2001), and it is estimated that such change in the weather could reduce the biodiversity in Asia, including the Korean Peninsula, and cause a great deal of environmental impacts such as diseases and floods.

In order to overcome the adverse effects on agriculture caused by a recent change in weather, the plant factory, which is capable of cultivating crops in a closed space regardless of the season or temperature, was developed (Kim 2010). The plant factory can be categorized into partial control type that uses natural and artificial light and complete control one that only uses artificial light (Kim 2010).

Since the partial control type can use sunlight as a light source, the power consumed by lighting equipment can be saved more than the full control type, but the disadvantage is that it is difficult to control the environment as it is affected by the external environment. In addition, it is difficult to expect uniform plant growth when a multi-stage bed is installed (Kim 2010). The full control type can control the precise environment and can manage the growth state stably regardless of the season. However, an alternative power saving is required because of the high amount of electricity consumed by the lighting equipment (Kim 2010).

Light-emitting diodes (LEDs), the light source used in this study, were installed by selecting a specific wavelength effective for the development of plants and photosynthesis. LEDs generate relatively low heat compared with high-pressure sodium lamp, fluorescent lamp, and hybrid electrode fluorescent lamp (HEFL), and it reduces the damage to the plants and consumes less electricity (Kim 2010). For its advantage, much research on the productivity and physiological response of flowers and crop plants such as chrysanthemum, Phalaenopsis, Petunia, rocket salad, lamb's lettuce, lettuce, cucumber, wheat, spinach, radish, tomato, and rice cultivated in glasses, in greenhouses, or in plant factories has been reported (Goins et al. 1997; Yorio et al. 2001; Matsuda et al. 2004; Trouwborst et al. 2010; Lu et al. 2012; Im et al. 2013; Kim et al. 2013; Kobayashi et al. 2013; Wojciechowska et al. 2013; Phansurin et al. 2017; Lee et al. 2017; Kim et al. 2018).

Silene capitata Kom. is a perennial herb that belongs to Caryophyllaceae which grows naturally in Mt. Naejang in South Korea and in the central part of North Korea (NIBR 2011). Their habitat characteristics are shaded places with less light compared to open areas and rock slopes with less moisture and available soil nutrients (NIBR 2011). These features of the habitat environment are suitable to utilize the limited conditions-it can reduce power consumption when cultivating by using less light and can grow even with less water and soil nutrients-of a plant factory. Also, it is easy to manage in a plant factory because the shoot height is small, growing up to $30 \mathrm{~cm}$ (NIBR 2011).

S. capitata forms a rosette, and the leaf of the peduncle is smaller than the rosette leaf. The pink color of the flower is clear and impressive compared to the green leaves. Through observations in this study, we found that the flowers are formed on the leaf axil as well as on the tips of the peduncles. It can bloom more than hundreds per plant in a certain environment (Park et al. 2016). The flowering period is from October to November, and it flowers throughout the month (NIBR 2011). But their basic ecological and physiological information is not well known. Therefore, a basic ecophysiological study should be preceded in order to develop a cultivation method of $S$. capitata for conservational purposes.

In this study, the optimal light environment for the growth and physiological response of $S$. capitata was investigated by using an LED light source by applying different duty ratios in the plant factory. We used the red+blue mixed light and red+blue+white mixed light as a light quality because red light and blue light which are mainly absorbed by chlorophyll and are known to regulate photomorphogenesis and photosynthesis are commonly used in a plant factory (Hopkins and Huner 2008).

White light wavelength is not well absorbed by a chlorophyll; they are absorbed by pigments such as carotenoids and anthocyanins (Hopkins and Huner 2008). For cucumbers (Cucumis sativus), the growth rate, carbon assimilation rate, and photon yield of PSII were higher under white single light than in purple, red, blue, green, and yellow single light (Wang et al. 2009). The photon yield of PSII $\left(F_{v} / F_{m}\right)$ of $S$. capitata was higher in $\mathrm{R}+\mathrm{B}+\mathrm{W}$ than in $\mathrm{R}+\mathrm{B}$ (Park et al. 2016). For Lactuca sativa var. capitata, the biomass of aboveground and underground part, dry mass, and sugar content were higher in $\mathrm{R}+\mathrm{B}+\mathrm{W}$ than in $\mathrm{R}$ $+B$ (Lin et al. 2013). Therefore, additional treatment of white light in red+blue mixed light may be more effective for plant growth and physiological responses. 
Duty ratio (DR), which is used as a power-saving measure in this study, is defined as the fraction of light-on-time to the light on-and-off cycle (Kim et al. 2014). Several studies reported that crop growth and physiological responses were affected when DR feeds on crops were controlled (Cho et al. 2013; Mori et al. 2002). Therefore, controlling DR in plant factories could be utilized as an energy-saving technique.

In this study, we investigated that $S$. capitata is grown well in a plant factory that affected on proliferation and production of plants and not affected on the external environment. The collected information could be available of basic data on an optimal and stable indoor cultivation technique for S. capitata.

\section{Methods}

\section{Cultivation and management}

For the purpose of this study, the seeds of $S$. capitata were sown on March 20, 2014, in the greenhouse located within Kongju National University. The seeds were sown on a basal plate $(60 \times 30 \times 3.5 \mathrm{~cm})$ filled with Hanareum horticultural bed soil (Shinsung Mineral, Goesan, South Korea), and they were watered every $2-3$ days until germination to prevent soil from drying out. The germinated seedlings were transplanted into round pots (diameter $12 \mathrm{~cm}$, height $15 \mathrm{~cm}$ ) also filled with Hanareum horticultural bed soil (Shinsung Mineral, Goesan, South Korea), and they were placed under seven light conditions (light chambers). Three plants were placed under each light condition. The plants were cultivated from June 2013 to March 2014. The transplanted seedlings were watered every 2-3 days to prevent the soil from drying out. Soil nutrients (Gold Soil, KGChemical, Ulsan, South Korea) containing organic matter (70\%), nitrogen (4.3\%), phosphoric acid (1.7\%), and potassium (1\%) were diluted in water and supplied at 7-day intervals.

During the cultivation period, the temperature inside the plant factory was maintained at $19.42 \pm 5.10{ }^{\circ} \mathrm{C}$ on average using a hot air heater (SS-2000, Zero Engineering, Daejeon, South Korea), and the humidity was maintained at an average of $71.81 \pm 9.22 \%$ using a humidifier (Fox-1H, Parus, Shanghai, China). Photosynthetic photon flux density (PPFD) in each chamber remained constant at an average of $150.89 \pm 23.05 \mu \mathrm{molm}^{-2} \mathrm{~s}^{-1}$, and the concentration of $\mathrm{CO}_{2}$ was $401.59 \pm 86.87 \mathrm{ppm}$. These environmental data were collected and managed every 10 min using a computer-based LCSEMS program (Parus, Shanghai, China). The day length was set at $16 \mathrm{~h}$ out of $24 \mathrm{~h}$ a day.

\section{Light conditions in the plant factory}

A total of seven light conditions were set inside the plant factory (Table 1) using "LED grow light system" developed by Parus (Shanghai, China). The size of the plant
Table 1 LED sources and duty ratios (\%) of seven treatments in the plant factory

\begin{tabular}{lll}
\hline LED source & Duty ratio (\%) & Treatments \\
\hline R+B & 95 & RB (95\%) \\
& 90 & RB (90\%) \\
& 85 & RB (85\%) \\
& 80 & RB (80\%) \\
& 75 & RB (75\%) \\
R+B+W & 85 & RBW (85\%) \\
& 70 & RBW $(70 \%)$ \\
\hline
\end{tabular}

factory is $360 \times 60 \times 230 \mathrm{~cm}^{3}$; it has three shelves in the container $\left(582 \times 334 \times 260 \mathrm{~cm}^{3}\right)$. The power consumption of each light source was $200 \mathrm{~W}$, and the size of the installed chamber (PGL-BOX, Parus, Shanghai, China) was $120 \mathrm{x} \times 52 \times 4.5 \mathrm{~cm}^{3}$, installed in each shelves in the plant factory. Red light $(\mathrm{R})$ and blue light $(\mathrm{B})$ were selected to create red+blue mixed light $(R+B)$ and red +blue+white mixed light $(\mathrm{R}+\mathrm{B}+\mathrm{W})$ conditions. The spectral wavelength range of $R$ and $B$ is generally known as 640-700 $\mathrm{nm}$ for R and 425-490 nm for B (Hopkins and Huner 2008). In this experiment, $R$ that showed the maximum peak at 630-660 $\mathrm{nm}$ range and $\mathrm{B}$ that showed the maximum peak at $440 \mathrm{~nm}$ in "LED grow light system" was used (Parus, Shanghai, China).

White light (W), which has the maximum peak at $450 \mathrm{~nm}$ and $540 \mathrm{~nm}$, was used, and the wavelength range containing green wavelength $(490-550 \mathrm{~nm})$ and yellow wavelength $(550-585 \mathrm{~nm})$ was used in addition to $\mathrm{R}$ and $\mathrm{B}$.

\section{Measurement of growth responses}

The total number of leaves per pot was counted in August 2013, and the length and width of three leaves per plant were measured in November to study the growth response of $S$. capitata. The leaves were selected in the upper, middle, and bottom part per plant. In March 2014, the number of shoots per plant which were budded at the roots was counted.

\section{Measurement of physiological responses}

To study the physiological response of S. capitata, photosynthetic rate $\left(\mu \mathrm{molCO}{ }_{2} \mathrm{~m}^{-2} \mathrm{~s}^{-1}\right)$, transpiration rate $\left(\mathrm{mmolm}^{-2} \mathrm{~s}^{-1}\right)$, stomatal conductance (mmol$\left.\mathrm{H}_{2} \mathrm{Om}^{-2} \mathrm{~s}^{-1}\right)$, and water use efficiency $\left(\mu \mathrm{molCO}_{2} \mathrm{~m}\right.$ $\mathrm{molH}_{2} \mathrm{O}^{-1}$ ) were measured with "Lci Ultra Compact Photosynthesis System" (ADC, Hoddesdon, UK) between 10:00 a.m. and 12:00 p.m. throughout October 2013. Chlorophyll content was measured using chlorophyll content meter (CCM-200, ADC, Hoddesdon, UK), and it was represented with chlorophyll content index (CCI), a unit measure of chlorophyll content that shows 
the difference of light absorption rate when $660 \mathrm{~nm}$ and $940 \mathrm{~nm}$ light is irradiated on the leaves. Using this method, the chlorophyll content was measured nondestructively (Richardson et al. 2002; Van den Berg and Perkins 2004). The photosynthetic rate, transpiration rate, stomatal conductance, water use efficiency, and chlorophyll content were measured 9 times repeatedly. Chlorophyll fluorescence $\left(F_{o}, F_{m}\right.$, and $\left.F_{v} / F_{m}\right)$ was measured with a chlorophyll fluorescence meter (OS30p, ADC, Hoddesdon, UK) to examine the environmental stress after dark adaptation for $20 \mathrm{~min}$ and was measured 18 times repeatedly. The leaves for measuring physiological responses were selected on the upper, middle, and bottom parts in each plant because the physiological responses can be different by the position of a leaf.

\section{Statistical analysis}

Statistical analysis of the growth and physiological responses of $S$. capitata was performed using statistical program Statistica 8 (Statsoft Inc., Tulsa, US). One-way ANOVA, which is a parametric statistical method, was used to analyze the data with normality and homoscedasticity. The data with no normality and homoscedasticity were tested using Kruskal-Wallis test, a nonparametric statistical method, with a 0.05 significance probability. The normality of each group was tested using the Shapiro-Wilk $W$ test, and the homoscedasticity was tested using Levene's test with 0.05 significance probability as the criterion. The ANOVA, Kruskal-Wallis post-hoc tests, Fisher's least significant difference and Dunn's test for multiple comparisons, the post-hoc tests of the ANOVA and Kruskal-Wallis test were were analyzed in $p<0.05$ (No and Jeong 2002).

\section{Results}

\section{Growth responses}

The leaf length was longest in RB $(80 \%) \geq \mathrm{RB}(85 \%)$, with RB (75\%), RBW (85\%), and RBW (70\%) $\geq$ RB (90\%) $\geq$ RB (95\%) following in descending order. In the $\mathrm{R}+\mathrm{B}$ condition, the leaf length was longest at $80 \% \mathrm{DR}$ and the shortest at 95\% DR. In the $\mathrm{R}+\mathrm{B}+\mathrm{W}$ condition, no difference was observed with change in DR (Fig. 1a). The leaf width was widest in RB (85\%), with $\geq \mathrm{RB}(75 \%) \geq \mathrm{RB}(80 \%) \geq \mathrm{RB}(90 \%), \mathrm{RBW}(85 \%) \geq$ RB (95\%), and RBW (70\%) following in descending order. In the $\mathrm{R}+\mathrm{B}$ condition, the leaf was widest at $85 \% \mathrm{DR}$ and narrowest at 95\% DR (Fig. 1a). There was no difference in the $\mathrm{R}$ $+\mathrm{B}+\mathrm{W}$ condition (Fig. 1a) and in the number of leaves and shoots among all treatments (Fig. 1b, c).

\section{Physiological responses}

Photosynthetic rate was highest in RBW (85\%), with RBW $(70 \%) \geq R B(95 \%), R B(90 \%), R B(80 \%)$, and RB $(75 \%) \geq \mathrm{RB}(85 \%)$ following in descending order (Fig. 2a). In the $\mathrm{R}+\mathrm{B}$ condition, the photosynthetic rate was lowest when DR was $85 \%$, but no difference was observed in the $\mathrm{R}+\mathrm{B}+\mathrm{W}$ condition (Fig. 2a). Transpiration rate was highest in $\mathrm{RB}(95 \%) \geq \mathrm{RB}(90 \%)$, with $\mathrm{RB}(80 \%)$, RBW $(85 \%) \geq \mathrm{RB}(85 \%), \mathrm{RB}(75 \%)$, and RBW (70\%) following in descending order. In the $\mathrm{R}+\mathrm{B}$ condition, the transpiration rate was highest at $95 \%$ DR and lowest at $85 \%$ and $75 \%$ DR (Fig. 2b). There was no difference in the R+B $+\mathrm{W}$ condition with the change in DR (Fig. 2b). Stomatal conductance was highest in RB $(95 \%) \geq \mathrm{RB}(90 \%)$, with $\mathrm{RB}(80 \%), \mathrm{RB}(75 \%), \mathrm{RBW}(85 \%) \geq \mathrm{RB}(85 \%)$, and RBW (70\%) following in descending order. In the $\mathrm{R}+\mathrm{B}$ condition, the stomatal conductance was highest at $95 \%$ and lowest at $85 \%$ DR (Fig. 2c). There was no difference in the $\mathrm{R}+\mathrm{B}+\mathrm{W}$ condition (Fig. 2c). Water use efficiency was highest in RBW (70\%) $\geq \mathrm{RB}$ (90\%), with RB (80\%), RB (75\%), RBW (85\%) $\geq \mathrm{RB}$ (95\%), and RB (85\%) following in descending order. No difference was observed with the change in $D R$ under the $R+B$ and $R+B+W$ conditions (Fig. 2d). Chlorophyll content was highest in RBW $(85 \%) \geq \mathrm{RB} \quad(95 \%)$, with RBW $(70 \%) \geq \mathrm{RB} \quad(80 \%)>\mathrm{RB}$ (90\%), RB (85\%), and RB (75\%) following in descending order. Chlorophyll content was highest at $95 \%$ and lowest at $90 \%, 85 \%$, and $75 \%$ DR under the $\mathrm{R}+\mathrm{B}$ condition (Fig. 2e). However, there was no difference in the $R+B$ $+\mathrm{W}$ conditions (Fig. 2e).

$F_{o}$ value was highest in RB (85\%), with RB $(80 \%) \geq \mathrm{RB}$ (95\%), RB (75\%) $\geq \mathrm{RB} \quad(90 \%) \geq \mathrm{RBW}$ (85\%), and RBW (70\%) following in descending order. In the $\mathrm{R}+\mathrm{B}$ condition, $F_{o}$ value was highest at $85 \%$ and $80 \%$ DR and lowest at $90 \% \mathrm{DR}$. But, there was no difference in $\mathrm{R}+\mathrm{B}+\mathrm{W}$ (Fig. 3a). $F_{m}$ value was highest in $\mathrm{RB}(80 \%) \geq \mathrm{RB}(85 \%) \geq$ RB (75\%), with RBW (85\%), RBW (70\%) $\geq$ RB (95\%), and $\geq \mathrm{RB}(90 \%)$ following in descending order. In the $\mathrm{R}+\mathrm{B}$ condition, $F_{m}$ value was highest at $80 \%$ and lowest at $90 \% \mathrm{DR}$. There was no difference in the $\mathrm{R}+\mathrm{B}+\mathrm{W}$ condition (Fig. 3a). $F_{v} / F_{m}$ value was highest in RBW (85\%), with RBW (70\%) > RB (95\%), RB (90\%), RB (85\%), RB (80\%), and RB (75\%) following in descending order, showing that the value is higher when white light is added (Fig. 3b). No difference was observed with different DRs in $\mathrm{DR}$ in $\mathrm{R}+\mathrm{B}$ and in $\mathrm{R}+\mathrm{B}+\mathrm{W}$ (Fig. $3 \mathrm{~b}$ ).

\section{Discussions}

The growth and physiological responses of S. capitata can be observed by subdividing the results into three conditions. The first is the response to the change in DR within the $\mathrm{R}+\mathrm{B}$ and $\mathrm{R}+\mathrm{B}+\mathrm{W}$ group. The second is the response to the light quality when DR is kept constant. The third is the response to both DR and light quality.

Within the $\mathrm{R}+\mathrm{B}$ group, leaf length and width are longest when DR was $80 \%$ and $85 \%$, respectively. Leaves showed a tendency to grow longer under lower DR (Fig. 1a). The lower the DR, the longer the time that light is not irradiated. Thus, in general, the amount of far-red light is more abundant during the dark period 


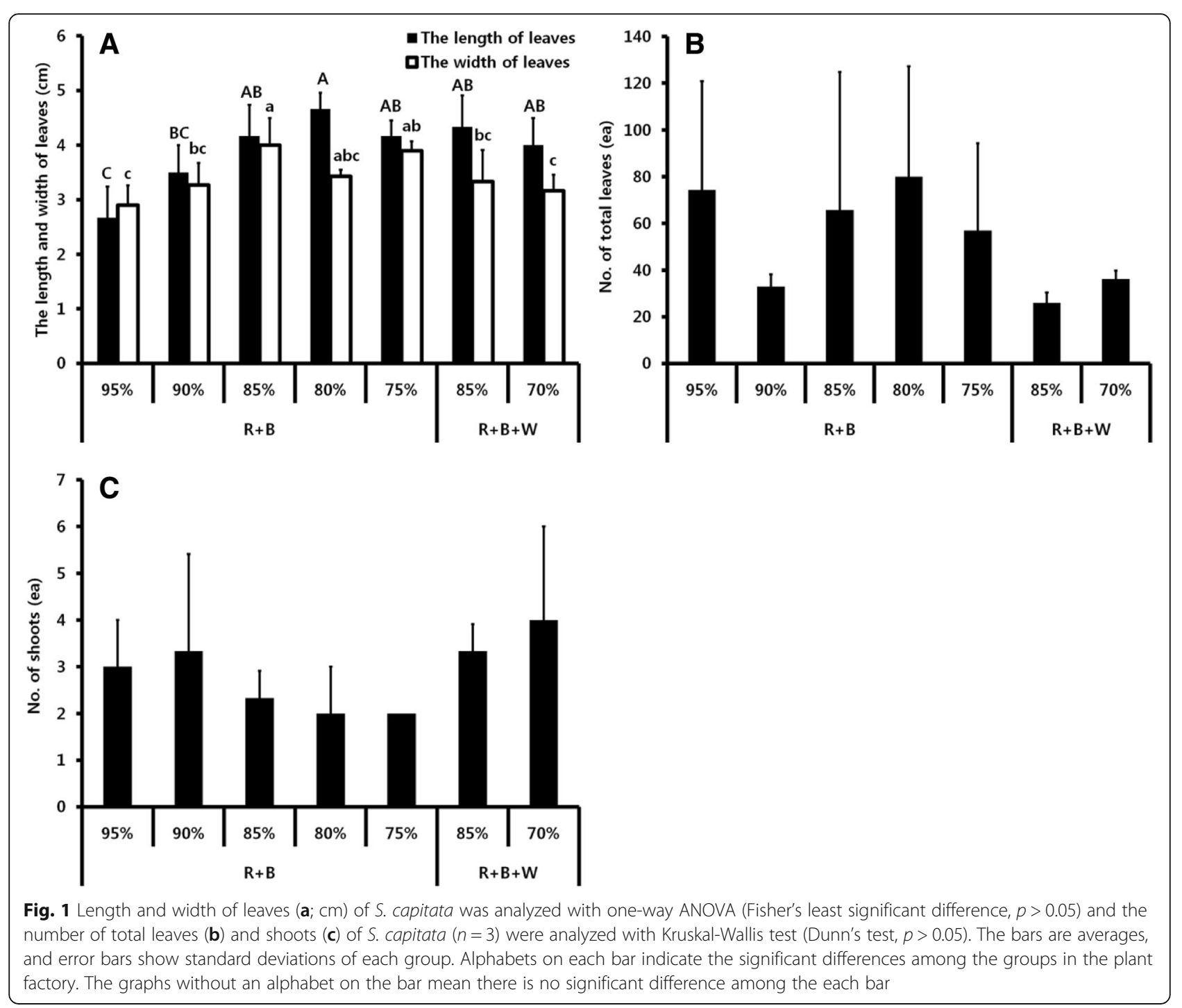

than in the red light, causing R:FR ratio to decrease and helping the stem, leaf, and petiole to grow better (Ballaré et al. 1990). Therefore, it seems that the length and width of the leaves of $S$. capitata grow longer with lower $\mathrm{DR}$ under $\mathrm{R}+\mathrm{B}$. Within the $\mathrm{R}+\mathrm{B}+\mathrm{W}$ group, there was no difference between 70 and $85 \%$ DR. When DR was constant at $85 \%$, there was no difference in the leaf length between RB (85\%) and RBW (85\%) conditions, but the leaf width was shorter in RBW (85\%) than in RB (85\%).

Considering both light quality and DR, there was no difference in leaf length between $\mathrm{R}+\mathrm{B}$ with $75-85 \% \mathrm{DR}$ and $\mathrm{R}+\mathrm{B}+\mathrm{W}$ with $70-85 \% \mathrm{DR}$, but they were longer than $\mathrm{R}+\mathrm{B}$ with $90-95 \%$ DR (Fig. 1a). In contrast, leaf width was greatest under $\mathrm{R}+\mathrm{B}$ with $75-85 \% \mathrm{DR}$, and there was no difference between $\mathrm{R}+\mathrm{B}$ with $90-95 \% \mathrm{DR}$ and $\mathrm{R}+\mathrm{B}+\mathrm{W}$ with 70-85\% DR (Fig. 1a). Considering that the environment treated with white light has $85 \%$ and $70 \%$ DR, there is no difference in the leaf length even when white light is additionally treated in a low DR environment, but it seems that the leaf width would be narrower.

The total number of leaves and the number of shoots of $S$. capitata were not different when treated with different DR under $\mathrm{R}+\mathrm{B}$ or with additional treatment of white light at $85 \%$ DR (Fig. 1b, c). The results obtained in this study is the same as the result of the study conducted by Park et al. (2016) that show the total number of leaves of S. capitata under continuous light (100\% DR) is not different in blue, red, white single light, red +far-red, red+blue, and red+blue+white mixed light conditions. Therefore, it is considered that the treatment of white light does not affect the total number of leaves and vegetative reproduction of S. capitata.

Similarly, the total biomass of Chrysanthemum coronarium var. spatiosum increased with higher DR towards $100 \%$ when they were cultivated in $R+B$ with $100 \%$, 99\%, and 97\% DR. But, the response to DR did 

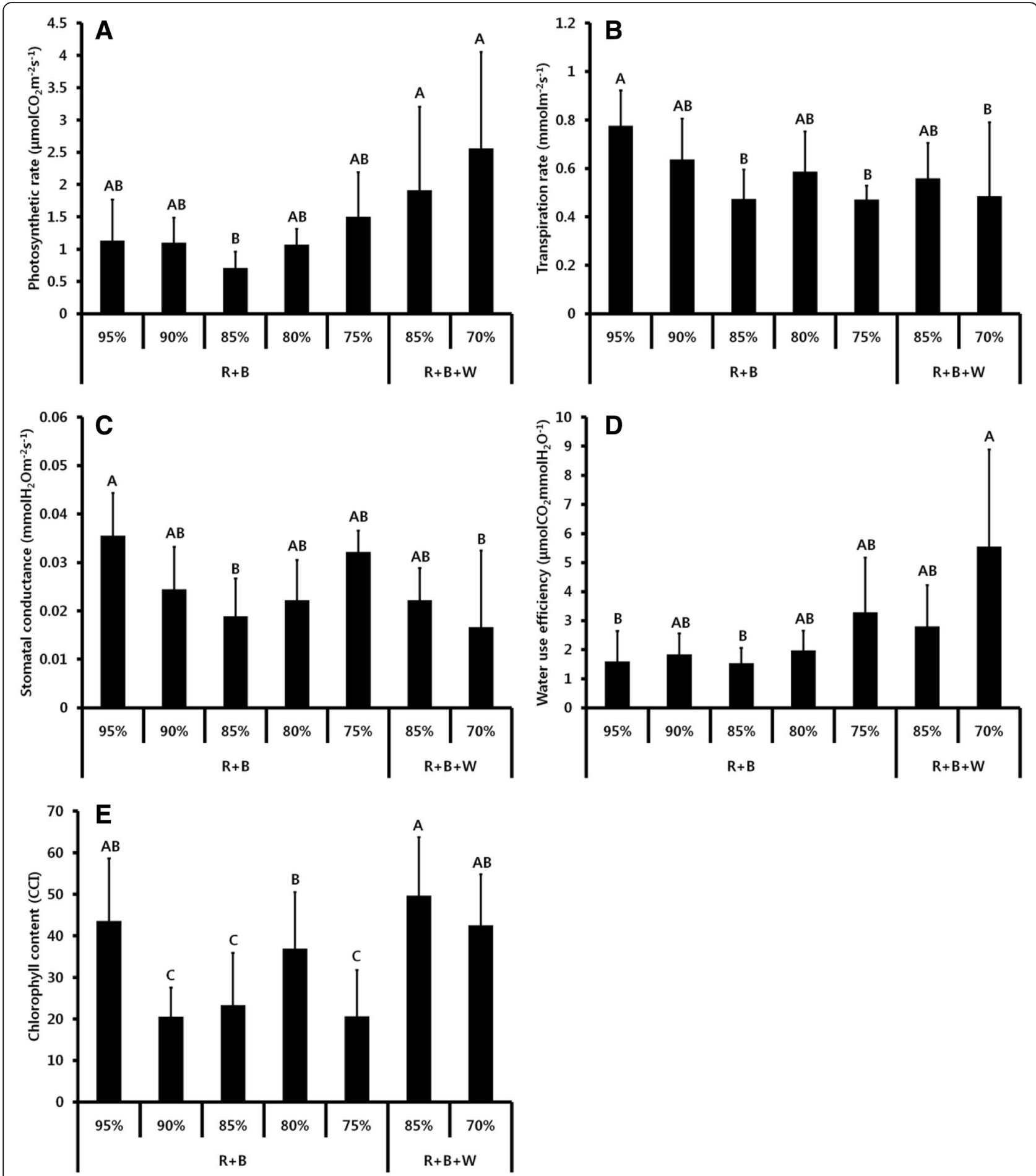

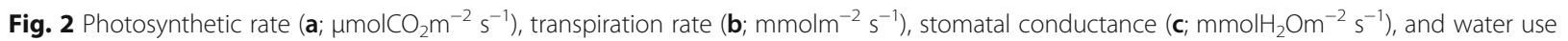
efficiency $\left(\mathbf{d} ; \mu \mathrm{molCO}{ }_{2} \mathrm{mmolH}_{2} \mathrm{O}^{-1}\right.$ ) were analyzed with Kruskal-Wallis test $(n=9$; Dunn's test, $p>0.05)$, and chlorophyll content (e; $\left.\mathrm{CCl}\right)$ in the leaves of S. capitata was analyzed with one-way ANOVA ( $n=9$, Fisher's least significant difference, $p>0.05)$. The bars are averages, and error bars show standard deviations of each group. Alphabets on the each bar indicate the significant differences among the groups in the plant factory

not appear when the light quality was set to $\mathrm{R}+\mathrm{B}+\mathrm{W}$ (Kim et al. 2014). Under the same condition, the total biomass of Brassica campestris var. chinensis was not different in $\mathrm{R}+\mathrm{B}$ environment unlike that of $C$. coronarium var. spatiosum. However, it was greater under $\mathrm{R}+\mathrm{B}$ + W with $97 \%$ DR than $\mathrm{R}+\mathrm{B}+\mathrm{W}$ with $100 \%$ and $99 \% \mathrm{DR}$ 

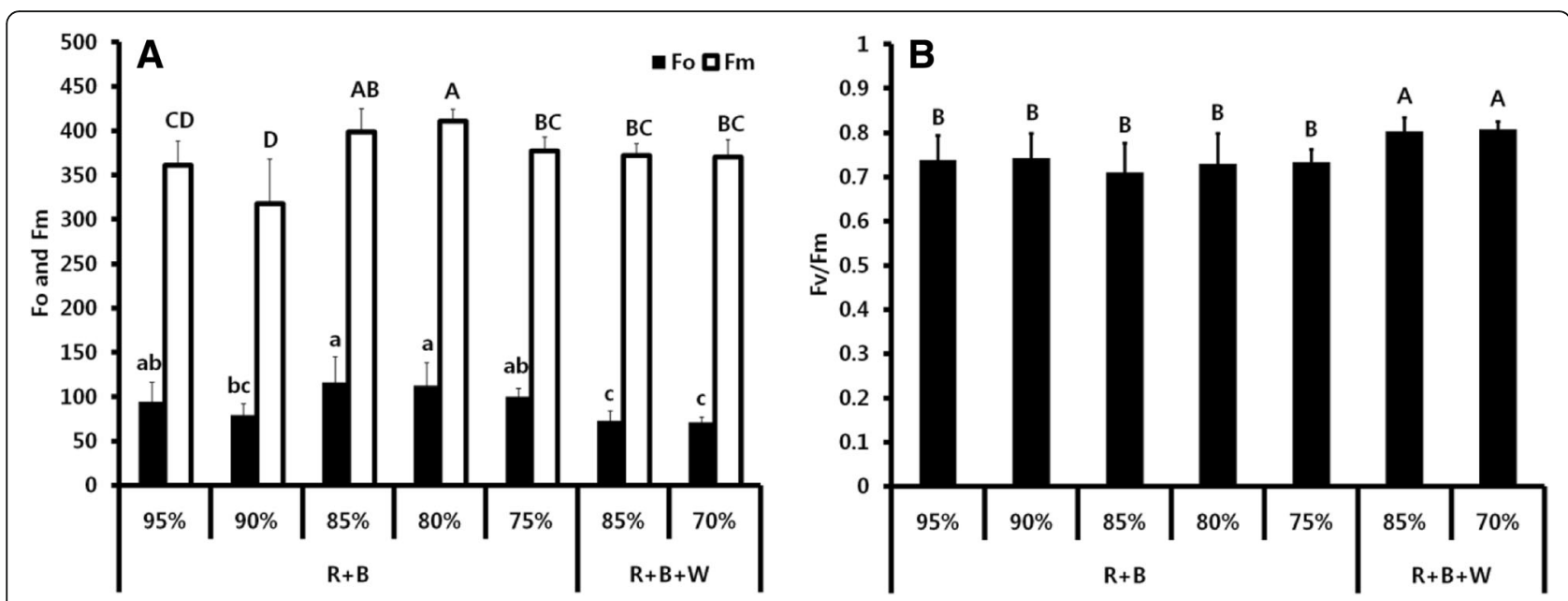

Fig. $3 F_{o}$ and $F_{m}(\mathbf{a})$ and $F_{v} / F_{m}(\mathbf{b})$ in the leaves of $S$. capitata were analyzed with Kruskal-Wallis test $(n=18$; Dunn's test, $p>0.05)$. The bars are averages, and error bars show standard deviations of each group. Alphabets on each bar indicate the significant differences among the groups in the plant factory

(Kim et al. 2014). It seems that these species respond differently to the light environment because they uniquely adapted themselves to various environmental stresses to survive and to thrive in the wild (Middleton 2001).

In the $\mathrm{R}+\mathrm{B}$ environment, the physiological response of $S$. capitata showed no difference in the photosynthetic rate and the water use efficiency with different DRs, but the stomatal conductance and the chlorophyll content were different (Fig. 2). These results suggest that, in the $\mathrm{R}+\mathrm{B}$ environment, the photosynthetic rate of $S$. capitata is not affected with controlled DR. Although the transpiration rate was different, the water use efficiency was indifferent to the change in DR. This would mean that the carbon-fixing ability would not be affected by DR when the same amount of water is supplied.

$F_{v} / F_{m}$ values were not affected with the change in DR, but $F_{o}$ and $F_{m}$ values were different (Fig. 3). $F_{o}$ is the minimum fluorescence value when the photosynthetic active light is absent, and $F_{m}$ is the maximum fluorescence value at maximum photochemical quenching (Maxwell and Johnson 2000). $F_{v} / F_{m}$ value indicates the maximum quantum yield of PSII, and it is 0.832 in most plant species (Bjorkman and Demmig 1987). Increasing $F_{o}$ value and decreasing $F_{v} / F_{m}$ value also indicate the photo-inhibiting damage caused by environmental stress (Maxwell and Johnson 2000). $F_{o}$ value was highest when DR was $85 \%$ and $80 \%$ although $F_{v} / F_{m}$ value did not differ with the change in DR (Fig. 3a, b). This result demonstrates that these environments have relatively higher environmental stress. Yet, the environmental stress was relatively low at 90\% DR (Fig. 3a).

Considering that $S$. capitata grows between rocks covered by canopy in the mountains, they are exposed to a stressful environment in which the plants have to photosynthesize using sunflecks, an irregular sunlight, caused by a developed forest crown. The crown reduces the amount of light quantity per day that reaches the forest floor. However, considering that the photosynthetic rate and water use efficiency did not differ with the change in DR (Fig. 2), the photosynthetic response would not be adversely affected if there is a stable water supply even though the light quantity reaching the forest floor is reduced. This is probably because $S$. capitata adapted to an irregular light quantity that reaches their habitat on the forest floor. But, in order to clarify this basic ecophysiology, it would be necessary to investigate their habitat environment in which they naturally grow and their physiological responses under various DR.

In $\mathrm{R}+\mathrm{B}+\mathrm{W}$, there was no difference in all measured physiological responses with the change in DR (Figs. 2 and 3). This suggests that there is no significant change in physiological activity even if DR is changed. However, $\mathrm{R}+\mathrm{B}+\mathrm{W}$ was treated with only two conditions, $85 \% \mathrm{DR}$ and $70 \%$ DR, in this experiment. Additional experiments should be conducted to determine whether there are differences under various DR conditions.

Photosynthetic rate and chlorophyll content of S. capitata were higher in RB (85\%) than in RBW (85\%) when DR was $85 \%$, but there were no differences in transpiration rate, stomatal conductance, and water use efficiency (Fig. 2). In other studies, photosynthetic rate of $S$. capitata was higher in $\mathrm{R}+\mathrm{B}+\mathrm{W}$ than in $\mathrm{R}+\mathrm{B}$ under continuous light $(100 \% \mathrm{DR})$. But, the chlorophyll content did not differ between $\mathrm{R}+\mathrm{B}$ and $\mathrm{R}+\mathrm{B}+\mathrm{W}$ treatments. It has been reported that chlorophyll content is produced more under the white single light than under the red and blue single light (Park et al. 2016). These results mean that lower DR would cause lower chlorophyll content if the environment lacks white light. 
In addition, the result of Park et al. (2016) showed that transpiration rate, stomatal conductance, and water use efficiency of $S$. capitata under the continuous light did not differ between $\mathrm{R}+\mathrm{B}$ and $\mathrm{R}+\mathrm{B}+\mathrm{W}$, which is similar to the result of this study. Therefore, photosynthetic rate increases and more chlorophyll is synthesized with additional white light if DR remains constant, but this does not seem to have a significant effect on water use efficiency. However, $F_{o}$ value is higher in RB $(85 \%)$ than in RBW (85\%), and $F_{v} / F_{m}$ value is higher in RBW (85\%) than in RB (85\%) (Fig. 3). This result is similar to the study conducted by Park et al. (2016) that $F_{v} / F_{m}$ was higher in $\mathrm{R}+\mathrm{B}+\mathrm{W}$ than in $\mathrm{R}+\mathrm{B}$ under continuous light. The addition of white light seems to alleviate the environmental stresses on S. capitata.

When photosynthetic rate and DR were considered together, photosynthetic rate, water use efficiency, and chlorophyll content were greater in $\mathrm{R}+\mathrm{B}+\mathrm{W}$ than in $\mathrm{R}+\mathrm{B}$ (Fig. 2). But, transpiration rate and stomatal conductance were highest in RB (95\%) and relatively low in RBW (70\%), showing a contrast (Fig. 2). It is thought that when white light is added, the amount of water released through pores is decreased and the photosynthetic rate is increased, resulting in higher water use efficiency. $F_{o}$ and $F_{v} / F_{m}$ values showed similar results. In both RBW (85\%) and RBW (70\%), $F_{o}$ value was the lowest but $F_{v} / F_{m}$ value was the highest (Fig. 3). This indicates that the environment treated with white light gives lesser environmental stress than those not treated with the white light irrespective of DR.

Considering the decrease in $F_{v} / F_{m}$ caused by the photoinhibition that occurs under environmental stress (Maxwell and Johnson 2000), the difference in $F_{v} / F_{m}$ value according to the light quality may be related to carotenoids which include the pigments of the xanthophyll cycle produced to protect the light-harvesting system from excessive light energy. Similarly, the seedlings of Nicotiana tabacum "Samsun" expressed more psy gene, which is a phytoene synthetase (precursor of carotenoids); bhy gene, which converts $\beta$-carotene to zeaxanthin; and $v d e$ gene, which converts violaxanthin to antheraxanthin and zeaxanthin, when the seedlings cultivated in the dark were irradiated with continuous red and white light than when they were irradiated with continuous blue light (Woitsch and Romer 2003). Therefore, if white light is treated in addition to red light and blue light, the environmental stress of $S$. capitata could be alleviated and water use efficiency could be improved.

\section{Conclusion}

These results suggest that the length of leaves would be longer in the low DR under $\mathrm{R}+\mathrm{B}$ condition. But the number of shoots and leaves would not be affected by DR and additional white light. Physiologically, it could be possible for $S$. capitata to photosynthesize more efficiently in a plant factory with relatively low water supply if white light is treated together with red and blue mixed lights and if DR is treated at $70 \%$ because this improves water use efficiency. Also, the tendency of $F_{o}$ value to decrease and $F_{v} / F_{m}$ value to increase indicates that the photoinhibition could be reduced with lower environmental stress. The power could also be saved with lower DR. A study with a similar result was reported in the past showing that $F_{v} / F_{m}$ value is highest in red+blue+white mixed light but relatively low in red+blue mixed light, red single light, and red+far-red mixed light when the DR was set at $100 \%$. But, the number of flowers was greater in red single light and in red+far-red mixed light than in red +blue+white light (Park et al. 2016). Considering this report, additional white light could prevent light stress on the leaf, but red and far-red light waves could enhance its reproductive responses. Thus, the study on basic ecophysiological and reproductive responses to various light environments should be carried out to cultivate $S$. capitata stably in the plant factory for its species conservation.

\section{Abbreviations \\ ANOVA: Analysis of variance; PPFD: Photosynthetic photon flux density}

\section{Funding}

This research was supported by Basic Science Research Program through the National Research Foundation of Korea (NRF) funded by the Ministry of Education (NRF-2018R1D1A1B07050269) and was supported by the National Research Foundation of Korea (NRF) grant funded by the Korean Government (MSIT) (No. NRF-2018R1A2B5A01021358).

\section{Availability of data and materials} Not applicable

\section{Authors' contributions}

All authors conducted the survey together during the study period. PJH wrote the manuscript. YYH participated in the design of the study and examined the manuscript. All authors read and approved the final manuscript.

Ethics approval and consent to participate Not applicable

\section{Consent for publication}

Not applicable

\section{Competing interests}

The authors declare that they have no competing interests.

\section{Publisher's Note}

Springer Nature remains neutral with regard to jurisdictional claims in published maps and institutional affiliations.

\section{Author details}

'Department of Biological Science, Kongju National University, Gongju-si 32588, Chungcheongnam-do, Republic of Korea. ${ }^{2} \mathrm{~K}$-water Convergence Institute, K-water, Yuseong-gu, Daejeon 34045, Republic of Korea. ${ }^{3}$ Division of Ecological Survey Research, National Institute of Ecology, Seocheon-gun 33657, Chungcheongnam-do, Republic of Korea. 
Received: 22 August 2018 Accepted: 18 October 2018

Published online: 06 November 2018

\section{References}

Ballaré CL, Scopel AL, Sánchez RA. Far-red radiation reflected from adjacent leaves: an early signal of competition in plant canopies. Science. 1990:247(4940):329-32. https://doi.org/10.1126/science.247.4940.329.

Bjorkman O, Demmig B. Photon yield of $\mathrm{O}_{2}$ evolution and chlorophyll fluorescence characteristics at $77 \mathrm{~K}$ among vascular plants of diverse origins. Planta. 1987;170:489-504.

Cho KJ, Cho JY, Park IS, Oh W. Effects of duty ratio of pulsed LED light on growth and photosynthetic rate of lettuce grown in a plant factory system. J Korean Soc People Plants Environ. 2013;16(6):427-34. https://doi.org/10.11628/ksppe. 2013.16.6.427

Goins GD, Yorio NC, Sanwo MM, Brown CS. Photomorphogenesis, photosynthesis, and seed yield of wheat plants grown under red lightemitting diodes (LEDs) with and without supplemental blue lighting. J Exp Bot. 1997;48(312):1407-13.

Hopkins W, Huner N. Introduction to plant physiology fourth edition. Hoboken: Wiley; 2008. p. 95-106.

Houghton JT, Ding Y, Griggs DJ, Noguer M, van der Linden PJ, Dai X, Maskell K, Johnson CA. Climate change 2001: the scientific basis. Cambridge: Cambridge University Press; 2001. p. 15-6.

Im JU, Yoon YC, Seo KW, Kim KH, Moon AK, Kim HT. Effect of LED light wavelength on chrysanthemum growth. Protected Horticulture and Plant Factory. 2013;22(1):49-54

Kim HT, Im JU, Yoon YC, Seo KW, Kim KH, Moon AK. Effect of LED light wavelength on chrysanthemum growth. Prot Hortic Plant Factory. 2013;22(1):49-54.

Kim JK, Yoon YJ, Kim KS, Sub Na JK, Choi KY. Effects of relative humidity and air injection on physiological and stomatal responses in phalaenopsis during acclimatization. Hort Sci Technol. 2018;36(2):193-201. https://doi.org/10. 12972/kjhst.20180020

Kim JW. Trend and direction for plant factory system. J Plant Biotechnol. 2010;37:442-55.

Kim SB, Lee KM, Kim HR, You YH. Effects of light sources, light quality on the growth response of leafy vegetables in closed-type plant factory system. Korean J Ecol Environ. 2014;47(1):32-40.

Kobayashi K, Amore T, Lazaro M. Light-emitting diodes (LEDs) for miniature hydroponic lettuce. Opt Photonics J. 2013;3(1):74-7.

Lee HJ, Chun JH, Kim SJ. Effects of pre harvest light treatments (LEDs, Fluorescent Lamp, UV-C) on glucosinolate contents in rocket salad (Eruca sativa). Hort Sci Technol. 2017;35(2):178-87. https://doi.org/10.12972/kjhst.20170021.

Lin KH, Huang MY, Huang WD, Hsu MH, Yang ZW, Yang CM. The effects of red, blue, and white light-emitting diodes on the growth, development, and edible quality of hydroponically grown lettuce (Lactuca sativa L. var. capitata). Sci Hortic. 2013;150(4):86-91.

Lu N, Maruo T, Johkan M, Hojho M, Tsukagoshi S, Ito Y, Ichimura T, Shinohara Y. Effects of supplemental lighting with light-emitting diodes (LEDs) on tomato yield and quality of single-truss tomato plants growth at high planting density. Environ Control Biol. 2012:50(1):63-74.

Matsuda R, Ohashi-Kaneko K, Fujiwara K, Goto E, Kurata K. Photosynthetic characteristics of rice leaves grown under red light with or without supplemental blue light. Plant Cell Physiol. 2004;45(12):1870-4.

Maxwell K, Johnson GN. Chlorophyll fluorescence-a practical guide. J Exp Bot. 2000;51(345):659-68.

Middleton L. Shade-Tolerant flowering plants: Adaptations and horti-cultural implications. Proc. XX EUCARPIA Symp. on New Ornamentals. 2001;552:95-102.

Ministry of Environment. White paper of environment. Sejong: Ministry of Environment; 2017. p. 47-9. pp 363-380

Mori Y, Takatsuji M, Yasuoka T. Effects of pulsed-red LD light on the growth of a plant. Laser Orig. 2002;30(10):602-5. https://doi.org/10.2184//sj.30.602.

NIBR (2011) https://species.nibr.go.kr. Accessed 24 Oct 2018.

No HJ, Jeong HY. Well defined statistical analysis according to Statistica. Seoul: Hyungseul Publisher; 2002. p. 535-56.

Park JH, Lee EP, Lee SI, Jang RH, An KH, You YH. Effects of the light source of LEDs on the physiological and flowering response of endangered plant Silene capitata Kom. Korean J Environ Ecol. 2016;30(5):821-8.

Phansurin W, Jamaree T, Sakhonwasee S. Comparison of growth, development, and photosynthesis of petunia grown under white or red-blue LED lights. Hort Sci Technol. 2017;35(6):689-99. https://doi.org/10.12972/kjhst.20170073.
Richardson AD, Duigan SP, Berlyn GP. An evaluation of noninvasive methods to estimate foliar chlorophyll content. New Phytol. 2002;153(1):185-94. https://doi.org/10.1046/j.0028-646X.2001.00289.x.

Trouwborst G, Oosterkamp J, Hogewoning SW, Harbinson J, Van leperen W. The responses of light interception, photosynthesis and fruit yield of cucumber to LED-lighting within the canopy. Physiol Plant. 2010;138:289-300.

Van den Berg AK, Perkins TD. Evaluation of a portable chlorophyll meter to estimate chlorophyll and nitrogen contents in sugar maple (Acer saccharum marsh.) leaves. For Ecol Manag. 2004;200(1-3):113-7.

Wang $\mathrm{H}$, Gu M, Cui J, Shi K, Zhou Y, Yu J. Effects of light quality on $\mathrm{CO}_{2}$ assimilation, chlorophyll-fluorescence quenching, expression of Calvin cycle genes and carbohydrate accumulation in Cucumis sativus. J Photochem Photobiol B Biol. 2009;96(1):30-7.

Woitsch S, Romer S. Expression of xanthophyll biosynthetic genes during lightdependent chloroplast differentiation. Plant Physiol. 2003;132(3):1508-17.

Wojciechowska R, Kołton A, Długosz-Grochowska O, Żupnik M, Grzesiak W. The effect of LED lighting on photosynthetic parameters and weight of lamb's lettuce (Valerianella locusta). Folia Hort. 2013;25(1):41-7.

Yorio NC, Goins GD, Kagie HR, Weeler RM, Sager JC. Improving spinach, radish, and lettuce growth under red light-emitting diodes (LEDs) with blue light supplementation. Hortscience. 2001;36(2):380-3.
Ready to submit your research? Choose BMC and benefit from:

- fast, convenient online submission

- thorough peer review by experienced researchers in your field

- rapid publication on acceptance

- support for research data, including large and complex data types

- gold Open Access which fosters wider collaboration and increased citations

- maximum visibility for your research: over $100 \mathrm{M}$ website views per year

At BMC, research is always in progress.

Learn more biomedcentral.com/submissions 